
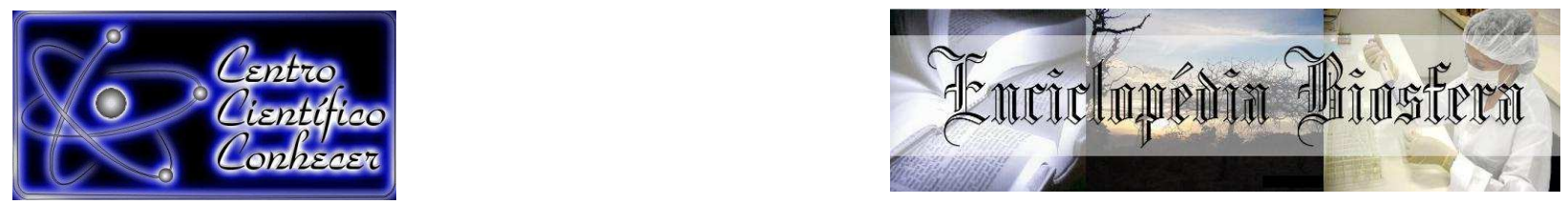

\title{
CONVOLVULACEAE DE UM FRAGMENTO DE RESTINGA, FORTALEZA, CEARÁ, BRASIL
}

\author{
${ }^{1}$ Francisco Diego Sousa Santos, ${ }^{2}$ Lucas Farias Pinheiro, ${ }^{3}$ Christopher Renner da \\ Silva Moraes, ${ }^{4}$ Marlene Feliciano Figueiredo.
}

1Biologo, Universidade Federal Rural de Pernambuco, Departamento de Botânica/Programa de Pós-Graduação em Botânica, Recife, PE (diego_biologiauva@hotmail.com)

2,3 Graduação em Ciências Biológicas, Univ.estadual do Ceará Fortaleza, CE

${ }^{4}$ Doutorado em ciências biológicas , Universidade Estadual Vale do Acaraú, Curso de Ciências Biológicas/Laboratório de Biologia Vegetal, Sobral, CE

Recebido em: 02/10/2017 - Aprovado em: 21/11/2017 - Publicado em: 05/12/2017 DOI: 10.18677/EnciBio_2017B78

\begin{abstract}
RESUMO
Convolvulaceae é composta por 58 gêneros e 1.880 espécies com distribuição predominante nas zonas tropicais e com alguns representantes nas zonas temperadas. O presente trabalho objetivou-se inventariar as espécies da família Convolvulaceae reportadas num fragmento de restinga com pequenas ilhas de mata seca. Foram registradas 12 espécies e cinco gêneros: Daustinia (1 sp.), Evolvulus L. (1 sp.) Ipomoea L. (6 spp.), Merremia Dennst. ex Endl. (3 spp.) e Operculina Manso (1 sp.). Apresentamos Chave para identificação dos táxons, descrição, comentários taxonômicos e distribuição geográfica.
\end{abstract}

PALAVRAS-CHAVE: Biodiversidade, restinga, taxonomia.

\section{CONVOLVULACEAE OF A FRAGMENT OF RESTINGA, FORTALEZA, CEARÁ, BRAZIL}

\begin{abstract}
Convolvulaceae consists of 58 genera and 1.800 species with distribution predominatly in tropical zone. The paper aimed to inventory the species of the Convolvulaceae family reported in a fragment of restinga with small islands of dry forest. Were recorded 12 species and five genera: Daustinia (1 sp.), Evolvulus L. (1 sp.) Ipomoea L. (6 spp.), Merremia Dennst. ex Endl. (3 spp.) and Operculina Manso (1 sp.). We present key for identification of the taxa, description, geographic distribution, taxonomic comments.
\end{abstract}

KEYWORDS: Biodiversity, restinga, taxonomy. 


\section{INTRODUÇÃO}

Convolvulaceae está inserida no clado das Asterids, na ordem Solanales (APG IV, 2016). Seu monofiletismo é sustentado por dados moleculares (STEFANOVIC et al., 2003). É representada por aproximadamente 1.880 espécies distribuídas em 58 gêneros (STAMPLE, 2012), com distribuição predominante na região tropical e alguns representantes nas zonas temperadas (STAMPLE, 2012). No Brasil, está representada por 405 espécies e 24 gêneros, ocorrendo em todos os domínios geográficos. Dentre estes, caatinga e cerrado destacam por representarem o centro de diversidade e endemismo da família (GFB, 2015).

As espécies ocorrem em todos os tipos de vegetação, desde campos rupestres a bordas de mata em formações florestais. No Nordeste brasileiro, são reportadas, até o momento, 217 espécies e 17 gêneros, enquanto que no estado do Ceará, a família está representada por 96 espécies e dez gêneros, sendo Ipomoea L. o mais representativo, seguido de Evolvulus L. e Jacquemontia. Choisy (GFB, 2015). A família pode ser reconhecida por apresentar hábito herbáceo, subarbustivo, arbustivo e principalmente volúvel. Suas folhas são alternas, simples ou compostas; corola gamopétala, com cores variadas, desde rosa, roxa, branca, azul, amarela e vermelha, e áreas mesopétalas bem delimitadas; cálice dialissépalo, com sépalas desiguais ou iguais; ovário supero e fruto tipo capsula (BURIL et al., 2013). Apesar de ser bem representada na flora brasileira, sua importância ambiental e ecológica ainda é pouco enfatizada (SIMÃO-BIANCHINI; PIRANI, 1997).

Algumas espécies destacam-se como invasoras, tais como lpomoea quamoclit L., I. nil (L.) Roth e I. megapotamica Choisy; outras são holoparasitas como as espécies de Cuscuta L. (SOUSA; LORENZI, 2008). Ao contrário de I. pescaprae (L.) R. Brown e l. imperati (vahl) Griseb. que são importantes na fixação de dunas litorâneas, protegendo-as contra a erosão eólica (GARIMA et al., 2016). Além disso, destaca-se em importância econômica, a exemplo da batata-doce (I. batatas (L.) Lam) (SOUSA; LORENZI, 2008).

Dentre as famílias mais diversas na Caatinga, Convolvulaceae destaca-se em vários inventários florísticos (SANTOS et al., 2014; BURIL et al., 2013), aparecendo entre aquelas com o maior número de espécies, especialmente de trepadeiras. Os estudos sobre a família na caatinga são recentes e insuficientes para obter um conhecimento mais preciso sobre sua diversidade no domínio fitogeográfico (JUNQUEIRA; SIMÃO-BIANCHINI, 2006; BURIL et al., 2013). Tendo em vista a necessidade de conhecer a distribuição das espécies para incentivar a preservação de ecossistemas passiveis de degradação, esse trabalho objetivou-se realizar 0 estudo florístico das espécies de Convolvulaceae do Campus Itaperi, corroborando a atual distribuição geográfica das espécies no Ceara, além de incrementar o conhecimento de sua flora.

\section{MATERIAL E MÉTODOS}

\section{Área de estudo}

A área de restinga localiza-se na região metropolitana de Fortaleza, região Norte do estado do Ceará, nas coordenadas geográficas $3^{\circ} 43^{\prime} 02^{\prime \prime} \mathrm{S}, 38^{\circ} 32^{\prime} 35^{\prime \prime} \mathrm{O}$. Essa área detém de solos com areias quartzosas marinhas; altitude de $16 \mathrm{~m}$; clima Tropical Sub-úmido; pluviometria média anual de $1338 \mathrm{~mm}$, com chuvas concentradas de janeiro à maio e temperatura média $\left(\mathrm{C}^{\circ}\right)$ de $26^{\circ}$ a $28^{\circ}$. A vegetação é composta pelo Complexo Vegetacional da Zona Litorânea e Floresta Perenifólia Paludosa Marítima (IPECE, 2016). 


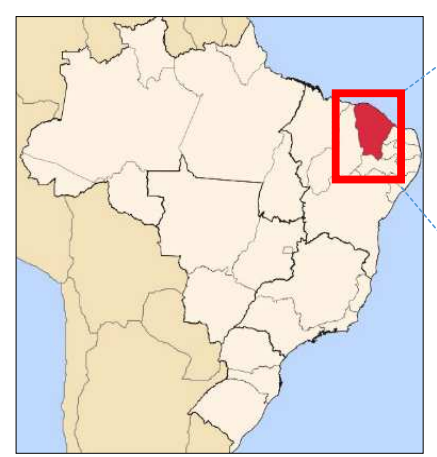

IPECE, 2016

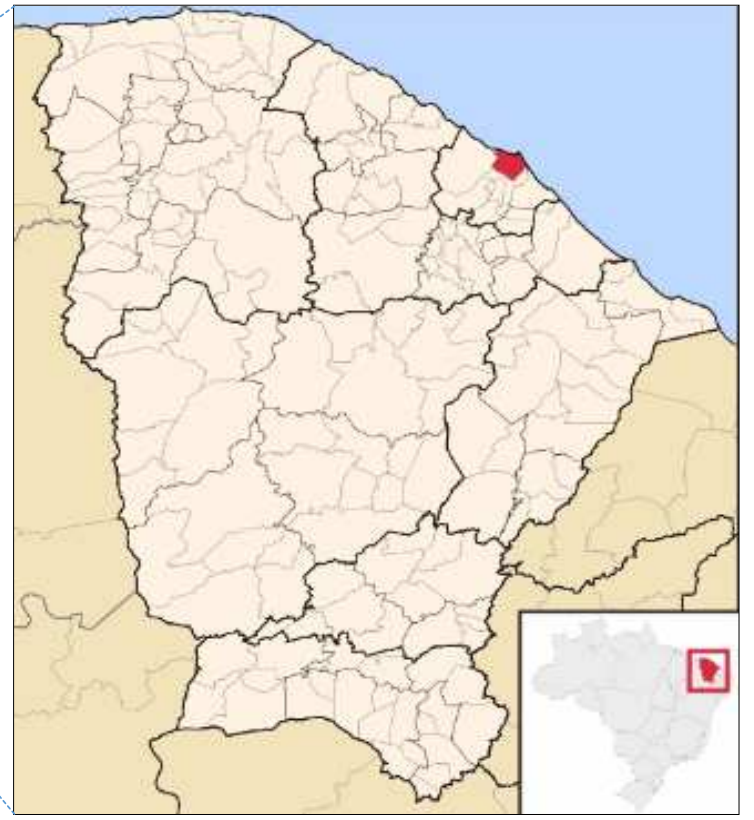

IPECE, 2016

\section{Procedimentos metodológicos}

As coletas foram realizadas em dez expedições de campo aleatórias, geralmente no período da manhã, ao longo de 2015 e 2016. As amostras foram processadas de acordo com as técnicas usuais em herborização (MORI et al., 1985) e posteriormente incorporadas ao acervo do Herbário Professor Afrânio Gomes Fernandes da Universidade Estadual do Ceará (UECE). A identidade dos táxons foi estabelecida com o auxílio de literatura especializadas (OOSTSTROOM, 1934; O'DONELL, 1941; BURIL et al., 2013) e comparação com espécies previamente identificadas. Os binômios das espécies estão de acordo com o IPNI (2012). Para as descrições morfológica, seguiu-se a proposta de Gonçalves e Lorenzi (2011). Os dados referentes ao hábitat das espécies foram referidos a partir de observações de campo. A distribuição geográfica foi estabelecida a partir de bibliografia (AUSTIN; HUAMAN, 1996) e sites especializados (GFB, 2015; TROPICOS, 2017).

\section{RESULTADOS E DISCUSSÃO}

$\mathrm{Na}$ área de estudo, foram registradas 12 espécies e 6 gêneros de Convolvulaceae, sendo Ipomoea o gênero mais representativo.

TRATAMENTO TAXONÔMICO

\section{Chave para identificação das espécies de Convolvulaceae}

1. Subarbusto com tricoma malpiguiaceo Evolvulus ovatus

1'. Trepadeira com tricoma simples.

2. Caule alado Operculina hamiltoni 
2'. Caule sem ala.

3. Folhas elípticas, flores em dicásios, capituliforme ......... Aniseia martinicensis

3'. Folhas cordiformes, flores em umbela, corola amarela .... Merremia umbelata

4. Folhas compostas.

5. Folhas com margem serreada e com indumento glanduloso

... M. cissoides

5'. Folhas com margem inteira e com indumento simples

4'. Folhas simples.

6. Folhas com margem serreada e corola amarela ... Daustinia montana

6'. Folhas com margem inteira e corola branca ou rosa.

7. Planta com folha lobada

M. dissecta

7'. Planta com folha inteira

8. Planta prostrada, folhas reniformes

Ipomoea asarifolia

8'. Planta trepadeira, folhas não reniformes.

9. Planta com sépalas rostrada I. bahiensis

9'. Planta com sépala não rostrada.

10. Planta com indumento piloso

longerramosa

10'. Planta com indumento hirsuto I. triloba

1. Aniseia martinicensis (Jacq.) Choisy Mém. Soc. Phys. Genève 8 (1): 661838.

Trepadeira, caule hirsuto. Lâmina foliar simples, 2,2 - 6,7 x 0,8 - 3,0 cm, oblanceolada, base cuneada, ápice emarginado, mucronado, margem plana, nervura peninérvea, concolor, pecíolo 0,2 - $1 \mathrm{~cm}$ compr., piloso a glabrescente. Inflorescência 1 - 3 flores, pedúnculo 2,5 - 5,0 cm compr., hirsuto, pedicelo 3,0 - 0,5 $\mathrm{cm}$ compr., viloso, bractéolas ca. $3 \mathrm{~mm}$ compr., lanceoladas, vilosas. Sépalas desiguais, 2 externas 1,3-1,6 x 0,6-0,7 cm, ovadas, base truncada, redonda, ápice agudo, reticuladas, vilosa, 1 intermediaria assimétrica, 2 interna menores 1,1-1,4 $\mathrm{x}$ $0,5-0,7 \mathrm{~cm}$, ovadas, base trucada a arredondada, ápice obtuso. Corola 2,0 - 2,5 $\mathrm{cm}$ compr., infundibuliforme, branca, area mesopetalas vilosas. Fruto oval. Sementes $3-4$, tricomas restritos a região hilar.

Material examinado: Brasil, Ceara, Fortaleza, Campus do Itaperi, Fortaleza, 24. VII.2016. fl., fr., Pinheiro, L.F. 25 (UECE).

Distribuição e comentário taxonômico: A espécie é distribuída ao longo das Américas (TROPICOS, 2017). No Brasil, distribui-se nos domínios fitogeográficos de Caatinga e Amazônia (GFB, 2015). Pode ser facilmente reconhecida na área de estudo por apresentar folhas em dicásio e inflorescência capituliforme.

2. Daustinia montana (Moric.) Buril \& A. R. Simões Phytotaxa 197(1): 60. 2015

Erva prostrada, caule hirsuto, entrenos 2,5 - 5,5 cm compr. Lâmina 1,3 - 2,5 x 0,6 $1,7 \mathrm{~cm}$, ovada, a lanceolada, pubescente, margem serreada, concolor, ápice obtuso, mucronado, base truncada a obtusa, pecíolo $0,3-2,3 \mathrm{~cm}$ compr., hirsuto. Inflorescencia capituliforme, brácteas externas foliáceas, elípticas, base atenuada, ápice agudo, obtuso, pubescente, pedúnculo 2,5 - 7,5 cm compr., hirsuto, pedicelo 
ca. $4 \mathrm{~mm}$ compr., hirsuto. Sépalas ca. $5 \mathrm{~mm}$ compr., elípticas, base truncada, ápice obtuso. Corola ca. 1,5 cm diâm, infundibuliforme, amarela. Fruto não observado.

Material examinado: Brasil, Ceará Fortaleza, Campus do Itaperi, 04.VII.2015, fl., Silva, H.O. et al. 32 (UECE).

Distribuição e comentário taxonômico: A espécie é endêmica do Brasil, distribuídas nas regiões Nordeste e Sudeste. O táxon ocorre nos domínios Caatinga e Cerrado (GFB, 2015). Na área de estudo, o táxon pode ser reconhecido por apresentar folhas com margem serreada e corola amarela.

\section{Evolvulus ovatus Fernald Proc. Amer. Acad. Arts 33(5): 891897}

\section{Figura 1A}

Subarbusto, ca. $45 \mathrm{~cm}$ alt., caule liso, piloso. Lâmina foliar simples, 0,8 - 3,0 x 0,5 $1,4 \mathrm{~cm}$, séssil, disposição imbricada em direção ao ápice, elíptica na base, estreito ovada em direção ao ápice, ápice obtuso, base truncada, arredondada, subcordada, margem plana. Inflorescência uniflora, pedúnculo ausente, pedicelo ca. $2 \mathrm{~cm}$ compr., piloso. Bractéolas ca. $1,5 \mathrm{~mm}$ compr., lanceoladas, pilosa. Sépalas iguais, ca. de 5 $\mathrm{mm}$ compr., ápice agudo, base cuneada. Corola ca. $5 \mathrm{~mm}$ compr., infundibuliforme, azul. Fruto globoso compresso. Sementes $1-3$.

Material examinado: Brasil, Ceará, Fortaleza, Campus do Itaperi, 24. VII.2016. fl., fr., Pinheiro, L.F. 27 (UECE).

Distribuição e comentário taxonômico: A espécie é distribuída desde o México até a América do Sul (TROPICOS, 2017). No Brasil, a espécie ocorre no Norte, Nordeste, Centro-Oeste e Sudeste, no domínio da caatinga, em diversos tipos de vegetação (GFB, 2015). Na área de estudo, a espécie pode ser reconhecida por apresentar hábito herbáceo com folhas ovadas e corola ca. $5 \mathrm{~mm}$ compr., azul.

4. Ipomoea asarifolia (Desr.) Roem. \& Schult. Syst. Veg. 4: 251. 1819.

Prostrada, caule liso, glabro. Lâmina 4-6 x $3-9 \mathrm{~cm}$, reniforme, ápice arredondado, emarginado, base cordada, margem plana, glabra, concolor, pecíolo $4-10 \mathrm{~cm}$ compr., glabro, liso. Inflorescência 3 - 8 flores, pedicelo 0,4 - 0,8 cm compr., glabro. Sépalas desiguais, 2 externas $5 \times 3 \mathrm{~mm}$, oblongas, ápice obtuso, redondo, base obtusa, glabra, 3 internas 1,2 - 1,3 x 0,4-0,5 cm, oblanceoladas, ápice obtuso, base atenuada, glabra, margem escabra. Corola 5,5-6,6 cm compr., glabra, roxa. Fruto não observado.

Material examinado: Brasil, Ceará, Fortaleza, Campus do Itaperi, 24. VII.2015. fl., fr., Almeida, F.B. 19 (UECE).

Distribuição e comentário taxonômico: Distribuídas ao longo das Américas (TROPICOS, 2017). No Brasil, ocorre nas regiões Norte, Nordeste, Centro-Oeste e Sudeste, nos domínios Mata Atlântica, Amazônia e Caatinga (GFB, 2015). Na área de estudo, a espécie pode ser facilmente reconhecida pela presença de folhas reniformes. 
5. Ipomoea bahiensis Willd. ex Roem. \& Schult. Syst. Veg. (ed. 15 bis) 4: 7891819.

Figura 1B

Trepadeira, caule glabrescente, torcido. Lâmina 3,0 - $10 \times 1,2-5,0 \mathrm{~cm}$, hastata, ápice agudo, base hastata, margem plana, glabrecente, concolor, pecíolo 0,5-4,0 $\mathrm{cm}$ compr., canaliculado, glabrescente. Inflorescência dicásio, 2 - 15 flores, pedúnculo 1,5 - $9 \mathrm{~cm}$ compr., glabrescente, pedicelo $0,3-0,5 \mathrm{~cm}$ compr., glabrescente. Sepalas $0,4-0,5 \times 3,0-4,0 \mathrm{~cm}$, oval, elíptica, base truncada, arredondada, obtusa, com rostro subapical, glabra, margem escabra. Corola 3,5 $4,0 \times 3,0-3,5 \mathrm{~cm}$, sericea, rosa. Fruto ca. $6 \mathrm{~mm}$ compr., ovoide, glabro. Sementes lanosas.

Material examinado: Brasil, Ceará, Fortaleza, Campus do Itaperi, 29. VII.2016. fl., fr., Barbosa, T.L.R. 42 (UECE).

Distribuição e comentário taxonômico: A espécie é endêmica do Brasil, distribuída nas regiões Norte, Nordeste, Sudeste e Centro-Oeste, nos domínios fitogeográficos Caatinga e Mata Atlântica (GFB, 2015). Na área de estudo, a espécie pode ser facilmente reconhecida pela presença de rostro subapical nas sépalas.

6. Ipomoea longerramosa Choisy Prodr. 9: 384. 1845.

Figura 1C

Trepadeira, caule estriado, torcido, piloso, glabrescente. Lâmina palmatissecta, 1,5 $2,5 \times 1,4-3 \mathrm{~cm}$, base obtusa, ápice agudo, glabrescente, pecíolo $0,6-2,0 \mathrm{~cm}$ compr., piloso. Inflorescencia em dicásio, $2-5$ flores, pedúnculo 0,5 - 7,3 cm compr., glabrescente, pedicelo $0,3-1,0 \mathrm{~cm}$ compr., glabro. Bractéolas ca. $1 \mathrm{~mm}$ compr., lanceolada, glabra. Sépalas 0,6-0,7 x 0,3 cm, lanceoladas, ápice agudo, base atenuada, margem não escariosa. Corola ca. $4 \mathrm{~cm}$ compr., sericea, amarela. Fruto ca. $8 \mathrm{~mm}$ compr., ovoide, glabra. Sementes glabrescente, $4-5 \mathrm{~mm}$ compr.

Material examinado: Brasil, Ceará, Fortaleza, Campus do Itaperi, 24. VII.2016. fl., fr., Pinheiro, L.F. 43 (UECE).

Distribuição e comentário taxonômico: A espécie é citada para o Brasil e Venezuela (TROPICOS, 2017). No Brasil, ocorre nas regiões Norte, Nordeste, Sudeste e Centro-Oeste, nos domínios da caatinga e cerrado (GFB, 2015). Na área de estudo, pode reconhecida por apresentar folhas palmatissecta e corola amarela.

7. Ipomoea triloba L. Sp. PI. 1:161 1753.

Figura 1D

Trepadeira, caule e ramos hirsutos, glabrescentes. Lâmina 2,0 - 10,5 x 1,3-9,5 cm, cordiforme, base cordada, ápice acuminado a agudo, margem inteira, pilosa a glabrescente, levemente descolor; pecíolo $2,0-12 \mathrm{~cm}$, piloso a glabrescente. Cimeira 2 - 10 flores, pedúnculo 0,9 - $10 \mathrm{~cm}$ compr., piloso a glabrescente, anguloso, pedicelo 0,2-1,0 cm compr., piloso. Bractéolas 0,2 - 1,1 x 0,1 cm, estreitamente triangularares a lanceoladas, base truncada, ápice acuminado, pilosa a glabrescente. Sépalas $0,8-0,9 \times 0,4-0,5 \mathrm{~cm}$, elípticas a naviculares, base truncada, ápice acuminado a agudo, as externas pilosas a setosas; as internas 
glabras. Corola $1,5-2,5 \times 2,0-2,5 \mathrm{~cm}$, infundibuliforme, área mesopétala glabra a glabrescente, branca. Cápsula ca. 0,6 cm, globosa, hirsuta no ápice, deiscente, apiculada. Sementes $0,4-4,5 \mathrm{~mm}$ compr., glabras.

Material examinado: Brasil, Ceará, Fortaleza, Itaperi, 22.VII.2015, fl., Pinheiro, L.F. 28 (UECE).

Distribuição e comentário taxonômico: Amplamente distribuída nas Américas (Tropicos 2017) e no Brasil, onde ocorre de forma naturalizada nos domínios da Amazônia, Caatinga, Cerrado e Mata Atlântica (GFB, 2015). Pode ser reconhecida por apresentar sépalas naviculares a elípticas, cápsula com ápices hirsutos e corola branca.

8. Merremia aegyptia (L.) Urb. Symb. Antill. 4(3): 505. 1910.

\section{Figura 1E}

Trepadeira, caule liso, hirsuto. Lâmina 5-folioladas, folíolos 2,1-13 cm x 1,1-7,0 $\mathrm{cm}$, elípticos, base cuneada, ápice acuminado, pubescentes, margem inteira, pecíolo 0,6 - $14 \mathrm{~cm}$ compr., hirsuto. Inflorescência dicásio, 3 - 8 flores, pedúnculo 4,0 - 13 $\mathrm{cm}$ compr., hirsutos, $\square$ mbellate $\square 0,2-0,6 \mathrm{~cm}$, lanceoladas, pedicelo $0,7-4,0 \mathrm{~cm}$ compr., hirsutos. Sépala 1,0-2,0 × 0,4-0,8 cm, lanceolada a estreito ovada, ápice atenuado, base truncada, hirsuta. Corola ca. $2,5 \mathrm{~cm}$ compr., infudibuliforme, glabra, branca. Fruto não observado.

Material examinado: Brasil, Ceará, Fortaleza, Campus do Itaperi, 24. VII.2016. fl., Pinheiro, L.F. 32 (UECE).

Distribuição e comentário taxonômico: A espécie ocorre ao longo das Américas Central e Sul (TROPICOS, 2017). No Brasil, apresenta ampla distribuição, exceto na região Sul. Possui distribuição nos domínios Amazônia e Caatinga (GFB, 2015). No Campus Itaperi, a espécie pode ser reconhecida por apresentar folhas compostas com indumento hirsuto.

\section{Merremia $\square$ mbellate (L.) Hallier f. Bot. Jahrb. Syst. 16 (4-5): 552. 1893.}

Trepadeira, caule glabro. Lâmina $4-11 \times 2,8-6,5 \mathrm{~cm}$, ovada a lanceolada, velutina, margem plana, concolor, ápice agudo, base cordada, ápice cordada, pecíolo 1,5 - 3 $\mathrm{cm}$ compr., velutino. Inflorescencia em umbela, $3-15$ flores, pedúnculo $1-2 \mathrm{~cm}$ compr., glabrescente. Bractéolas lanceoladas. Sepalas $1-1,1 \times 0,5-0,6 \mathrm{~cm}$, elípticas, margem escariosa, glabra. Corola ca. $3 \mathrm{~cm}$ compr., sericea, amarela. Fruto ca. $1 \mathrm{~cm}$ compr., globoide, glabro. Sementes velutinas.

Material examinado: Brasil, Ceará, Fortaleza, Campus do Itaperi, 24. VII.2016. fl., fr., Pinheiro, L.F. 37 (UECE).

Distribuição e comentário taxonômico: A espécie possui distribuição ao longo das Américas e alguns países do velho mundo (TROPICOS, 2017). No Brasil, ocorre em todas as regiões, nos domínios Cerrado e Mata Atlântica (GFB, 2015). Pode ser facilmente reconhecida por apresentar flores em umbela.

10. Merremia cissoides (Lam.) Hallier f. Bot. Jahrb. Syst. 16(4-5): 552. 1893. 
Trepadeiras herbáceas; Entrenós pubescentes, com tricomas glandulares, 2,5 - 15,0 cm compr. Folhas 5-6-folioladas, folíolos 2,0-4,0 x 0,4-1,8 cm, elípticos, ápice agudo a mucronado, base atenuada a cuneada, margem denteada, glabrescentes. Pecíolo 0,6 - 2,2 cm comp.; Flor isolada; pedúnculo 1,7 - 2,3 cm compr., pubescente, bractéolas $0,6-1,0 \mathrm{~cm}$ comp., lanceoladas; pedicelo $0,4-0,8 \mathrm{~cm}$ compr.; sépalas subiguais, externas $1,2 \times 0,5 \mathrm{~cm}$, ovais, ápice agudo, base cuneada, internas $1,4 \times 0,5 \mathrm{~cm}$, ovais, ápice atenuado, base cuneada, glabras. Corola $3,8 \mathrm{~cm}$ compr., infudibuliforme, glabra, branca com a fauce do tubo vinácea. Fruto ca. $1 \mathrm{~cm}$, semente $0,4 \mathrm{~cm}$, globosa.

Material examinado: Brasil, Ceará, Fortaleza, Campus do Itaperi, 24. VII.2016. fl., fr., Pinheiro, L.F. 38 (UECE).

Distribuição e comentário taxonômico: A espécie ocorre desde o México a Argentina (TROPICOS, 2017). No Brasil, ocorre em todas as regiões e domínios fitoecológicos (GFB, 2015). A espécie pode ser reconhecida por apresentar indumento glanduloso.

\section{Merremia dissecta (Jacq.) Hallierf. Bot. Jahrb. Syst. 16 (4-5): 552. 1893.}

Trepadeira, ramos hirsutos. Lâmina lobada, palmatipartida, $8-10 \mathrm{~cm} \times 10-13 \mathrm{~cm}$, hirsutos, $5-8$ segmentos, ápice mucronado, margem inteira, pecíolo $3,0-5,5 \mathrm{~cm}$ compr., hirsuto. Inflorescência dicásio $3-6$ flores, pedúnculo ca. $8 \mathrm{~cm}$ compr., hirsuto, bractéolas ausentes, pedicelo $3,5-4,0 \mathrm{~cm}$ hirsuto. Sépalas desiguais, externas $2,0-2,4 \mathrm{~cm} \times 0,6 \mathrm{~cm}$, ovais, ápice arredondado a mucronado, base obtusa, hirsutas a glabrescentes. Corola 4,0-5,5 cm, campanulada, glabra. Fruto não observado.

Material examinado: Brasil, Ceará, Fortaleza, Campus do Itaperi, 24. VII.2016. fl., fr., Pinheiro, L.F. 40 (UECE).

Distribuição e comentário - No Brasil, ocorre em todas as regiões e domínios fitogeográficos (GFB, 2015). A espécie poder reconhecida, na área de estudo, por apresentar folhas lobadas com margem inteira.

12. Operculina hamiltoni (G. Don) D. F. Austin \& Staples J. Arnold Arbor. 64(3): 487-488. 1983

\section{Figura 1F}

Trepadeira, caule alado, glabro. Lâmina 2,3 - 7,8 x 1,5 - 6,3 cm. ovada, ápice agudo, acuminado, base cordada, glabra, concolor, margem sinuosa, pecíolo 1,4 $2,2 \mathrm{~cm}$ compr., glabro. Inflorescencia uniflora, bractéolas lanceoladas, glabra, escariosa, pedúnculo 1,8 - 5,2 cm compr., glabro, pedicelo 1,0-1,5 cm compr., glabro. Sépalas 2,3-2,6 × 1,0-1,4 cm, ovada, lanceolada, base obtusa, ápice obtuso, glabra, margem escariosa. Corola ca. $4 \mathrm{~cm}$ compr., campanulada, sericea, amarela. Fruto 1,0-1,3 cm compr., glabro. Semente ca. $7 \mathrm{~mm}$ compr., glabra.

Material examinado: Brasil, Ceará, Fortaleza, Campus do Itaperi, 24. VII.2016. fl., fr., Pinheiro, L.F. 33 (UECE).

Distribuição e comentário taxonômico: A espécie ocorre ao longo da América do Sul (TROPICOS, 2017). No Brasil, ocorre nas regiões Norte, Nordeste, Sudeste e Centro-Oeste, nos domínios Amazônia, Caatinga, Cerrado, Mata Atlântica e 
Pantanal (GFB, 2015). Na área de estudo, a espécie pode ser reconhecida por apresentar caule alado.

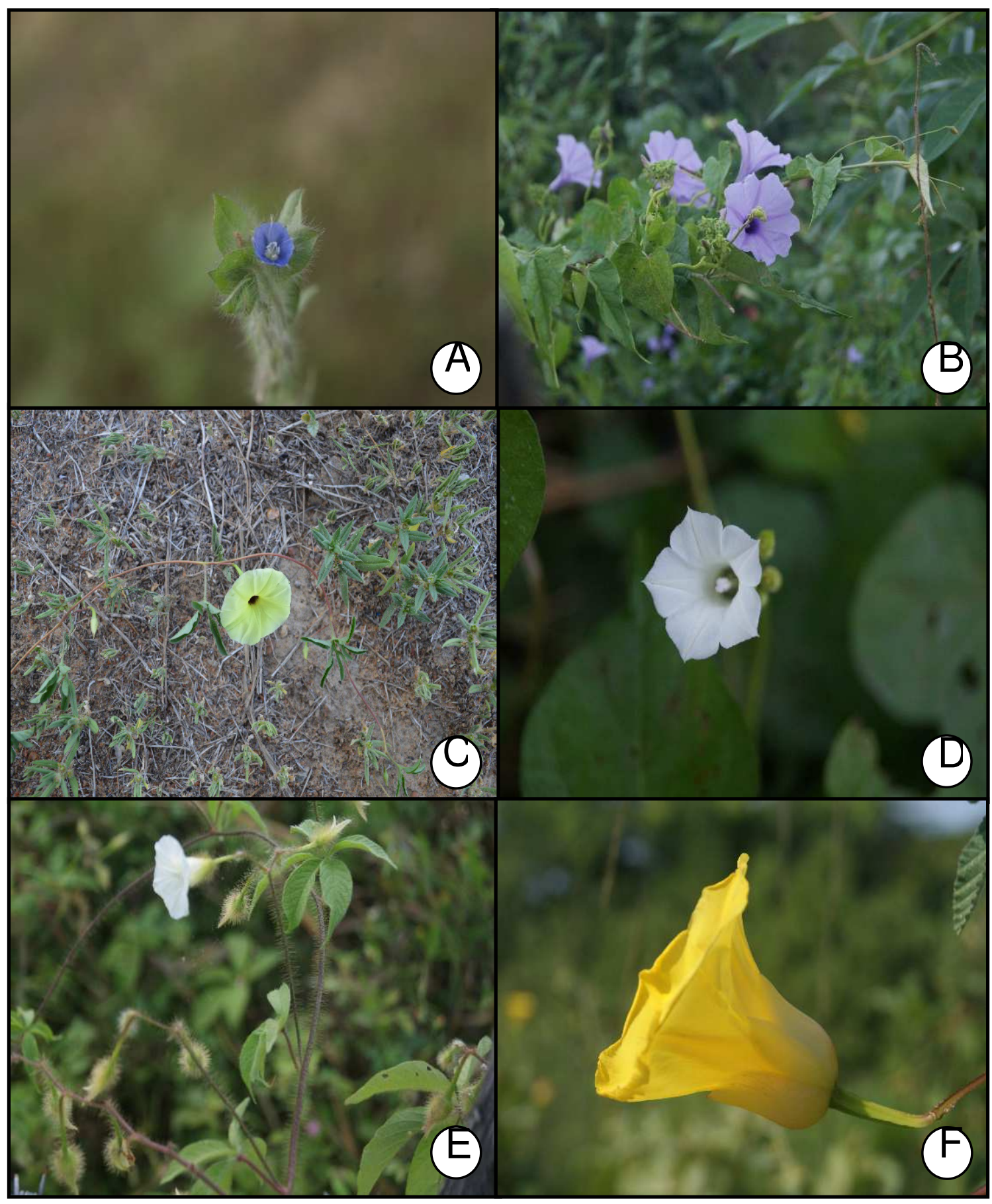

FIGURA 1. Espécies de Convolvulaceae coletadas em uma área de restinga, Fortaleza-CE. A. Evolvulus ovatus; B. Ipomoea banhiesis; C. I. longerramosa; D. I. triloba; E. Merremia aegyptia; F. Operculina hamiltonii. Fonte.Santos (2017). 


\section{REFERÊNCIAS}

APGIV. An update of the Angiosperm Phylogeny group classification for the orders and families of families flowering plants: APGIV. Botanical Journal of the Linnean Society.181:120,2016. doi: 10.1111/j.1095-8339.2009.00996.x

AUSTIN, D.F.; HUÁMAN, Z. A synopsis of Ipomoea (Convolvulaceae) in the Americas. Taxon 45: 3-38, 1996. Disponível em: http://links.jstor.org/sici?sici=00400262\%28199602\%2945\%3A1\%3C3\%3AASOI\%28I\%3E2.0.CO\%3B2-T

BFG. Growing knowledge: an overview of Seed Plant diversity in Brazil. Rodriguésia, v. 66, n. 4, 2015. http://dx.doi.org/10.1590/2175-7860201566411

BURIL, M.T.; DELGADO-JÚNIOR, G.C.; BARBOSA, M.R.V.; ALVES, M. Convolvulaceae do Cariri paraibano, PB, Brasil. Revista Nordestina de Biologia, v. 21: p.326, 2013.http://periodicos.ufpb.br/index.php/revnebio/article/view/12155/10185

GARIMA, O.; MISHRA, K.N.; MISHRA, A. Pharmacological Uses and Isolated Chemical Constituents of Ipomoea digitata: A Review. Journal of Pharmacy and Biological Sciences, v. 3: p. 01-04, 2016.doi:10.9790/3008-11030201004

GONÇALVES, E.G.; LORENZI, H. Morfologia Vegetal: Organografia e Dicionário llustrado de Morfologia das Plantas Vasculares. 2ed. São Paulo, SP: Instituto Plantarum de Estudos da Flora. p. 512, 2011.

ÍNDICE INTERNACIONAL DE NOMES DE PLANTAS (2012). Publicado na Internet http://www.ipni.org [acessado 15 de setembro de 2017].

IPECE - Instituto de Pesquisa e estratégia Econômica do Ceará . Fortaleza. Disponível em http://www.ipece.ce.gov.br. Acesso em 14 set. 2017.

JUNQUEIRA, M.E.R.; SIMÃO-BIANCHINI, R. O gênero Evolvulus L. (Convolvulaceae) no município de Morro do Chapéu, BA, Brasil. Acta Botanica Brasilica, v. 20, n. 1, p. 152-172, 2006. http://dx.doi.org/10.1590/S010233062006000100015

MORI, S.A.; MATTOS-SILVA, L.A.; LISBOA, G.; CORADIN, L. 1985. Manual de manejo do herbário fanerogâmico. CEPLAC/CEPEC, Ilhéus. 104p.

O'DONELL, C.A. Revision de las espécies americanas de Merremia. Lilloa, v. 6, p. 467-554, 1941.

OOSTSTROOM, S.J. VAN. A monograph of the genus Evolvulus. Meded. Mededeelingen van het Botanisch Museum en Herbarium van de Rijks Universiteit te Utrecht, v. 14, p. 1-267, 1934.

SANTOS, F.D.S; SOUSA, S.S.; NASCIMENTO, J.E.M.; ANDRADE, L.B.S.; FIGUEIREDO, M.F. Flora fanerogâmica do Sítio Santo Inácio, Meruoca-CE. Enciclopédia Biosfera,v.10,n.18,p.3291,2014.

http://www.conhecer.org.br/enciclop/2014a/CIENCIAS\%20BIOLOGICAS/flora.pdf 
SOUZA, V.C.; LORENZI, H. Botânica Sistemática. Guia ilustrado para identificação das famílias de Angiospermas da flora brasileira, baseado em APGll. Nova Odessa, Instituto Plantarum, p. 640, 2008.

STEFANOVIĆ, S.; AUSTIN, D.F.; OLMSTEAD, R.G. Classification of Convolvulaceae: A phylogenetic. Systematic Botany, v. 28, n. 4, p. 797-806, 2003. Disponível em: http://www.jstor.org/stable/25063924

STAPLES, G.W. 2012. Convolvulaceae Unlimited. http://convolvulaceae.myspecies. Acesso em 22 Jul 2012.

SIMÃO-BIANCHINI, R.; PIRANI, J.R. Flora da Serra do Cipó, Minas Gerais: Convolvulaceae. Boletim de Botânica, Universidade de São Paulo, v. 16, p. 125149, 1997. DOI: http://dx.doi.org/10.11606/issn.2316-9052.v16i0p125-149

TROPICOS.ORG. Missouri Botanical Garden. Disponível em: http://www.tropicos.org Acessado em: 08 Sep 2017. 